\title{
GLOBAL CONVERGENCE IN CONSTRUCTION
}

\author{
Guest Editor \\ Professor Sun Kuk KIM \\ Kyung Hee University, Korea
}




\title{
Guest Editorial
}

\section{GLOBAL CONVERGENCE IN CONSTRUCTION}

\author{
Sun Kuk KIM \\ Department of Architectural Engineering, Kyung Hee University, Yongin, Korea
}

Under the theme of "Global Convergence in Construction”, ICCEM-ICCPM 2009, sponsored by Korea Institute of Construction Engineering and Management (KICEM), was held successfully at Haevichi hotel near the coast of Jeju Island, from $27^{\text {th }}$ to $30^{\text {th }}$ of May, 2009. Since the $1^{\text {st }}$ International Conference on Construction Engineering and Management (ICCEM) was held in 2005, followed by the decision of International Program Committee (IPC) which is comprised of thirty-five members from ten countries, the $2^{\text {nd }}$ ICCPM-ICCEM 2007 organized by Nanyang Technological University (NTU), Singapore was held in 2007. At the time, as NTU was holding ICCPM (International Conference on Construction Project Management) every second year, NTU decided to hold both ICCPM and ICCEM 2007 together. ICCEM-ICCPM 2009 was held in Korea according to the IPC's decision that the conference could be held in Korea every second time since 2005, made upon the acknowledgement of KICEM's successful performance in founding and hosting ICCEM 2005.

Oral and poster presentation of ICCEM. ICCPM 2009 was made under following topics: 'Project Management', 'Project Delivery Systems', 'Cost, Time, Quality, and Safety Management', 'Design and Engineering Management', 'Claim and Dispute Resolution', 'Information Technology in Construction', 'Automation and Robotics in Construction', 'Construction
Productivity Improvement', 'Construction Education and Training', 'International and Global Issues in Construction Project Management', 'State-of-the-Art in Construction Engineering and Management', 'Sustainability and the Environment', 'Building Information Model'.

The organizing committee members, after the academic conference, selected five papers among the articles presented in the conference, which will be published in the special issue of IJSPM. The high quality research papers which have academic values to debate and discuss for the development of property management field are carefully selected to be published in the special issue. This Special Issue is expected to draw attention from interdisciplinary readers including academics, practitioners and consultants. The following is the contents of the papers summarized for readers.

K.L. Lin identifies key ecological indicators to motivate ecological concerns in urban land consolidation in the paper in which the author develops a practical urban ecological evaluation model with four levels and twenty-three indicators, utilizing habitual domain analysis and analytical hierarchy process.

S.K. Moon, S.H. Lee, K.M. Min, J.S. Lee, J.H. Kim and J.J. Kim survey landmark factors that can be quantitatively measured, collect data on super high rise residential buildings in Seoul. They find the intrinsic values of the landmarks, and analyze how these values 
differ in areas with different densities. It is expected that the results of this paper can be used to set an appropriate price of super high rise building in consideration of its landmark value in different area.

C.W. Koo, T.H. Hong, C.T. Hyun, S.H. Park and J. Seo present a paper to improve the effectiveness of a construction project in the public sector. The model developed in the paper requires the construction manager to engage in cost planning, depending on the owner's decision making at the early stages. This model was designed to coincide with the current practical process to reflect a future change in the construction environment, and to suggest trusted performance.

By using the numerical model developed in his paper, J. Jun evaluates the combined impact of MRG (Minimum Revenue Guarantee) and the RCP (Revenue Cap) agreements, which have been frequently used in BOT projects, on the project value based on the option pricing theory and to suggest a theoretical framework.
S. Hwang, M. Park, H.S. Lee, Y. Yoon and B.S. Son analyze the effect of the Korean government policies on mortgage lending on the housing and financing market in the paper. With an integrated perspective and an application of a system dynamics methodology, they proposes Korean Real Estate and Mortgage Market dynamics models based on the fundamental principles and causal loops of housing markets, which are determined by the economic activities of consumers, financial agencies, and real estate financing investors.

The guest editor sincerely believes that the papers included in this Special Issue would provide useful information for academic and practical dissemination and strategic property management. I would like to give my heartfelt words of gratitude to Prof. E.K. Zavadskas, Editor-inChief of the International Journal of Strategic Property Management, who helped in the preparation and editing of the papers. My sincere appreciation also goes to a panel of examiners who spent much time for a strictly impartial examination and supervision of the papers. 